\title{
EBSTEIN'S ANOMALY DIAGNOSED DURING LIFE
}

\author{
BY \\ C. B. HENDERSON, FREDERIC JACKSON, AND W. G. A. SWAN
}

From the Regional Cardiovascular Department, Newcastle General Hospital

The downward displacement into the right ventricle of a deformed tricuspid valve is the characteristic feature of Ebstein's anomaly. There is a large proximal cavity composed of the right atrium and part of the right ventricle and a distal cavity formed by the rest of the right ventricle. There is usually a large defect of the atrial septum. The association of the lesion with cardiac arrhythmia and bundle branch block has been stressed by Taussig (1947) and Brown (1950). Engle et al. (1950) reviewed the reported cases and, with three of their own, brought the total number to 26 at that time. None had been diagnosed before death. Baker et al. (1950) reported two cases with necropsy control in one of which crural embolism followed cardiac catheterization. Reynolds (1950) published the first report of a case diagnosed during life; angiocardiography and cardiac catheterization showed evidence of a very large right atrium and a defect of the atrial septum. Soloff et al. (1951) also made the diagnosis in life mainly on angiocardiographic evidence. van Lingen et al. (1952) described two further cases in which the diagnosis was suggested by catheter findings.

\section{Case Report}

A man, aged 26, was found to have an abnormal heart at the age of four and on medical advice he led a restricted life, avoiding strenuous exertion, but was able to work as a mining engineer. Two days before admission he felt rapid palpitation after cycling and his breathing became distressed. On admission he was noted to be a well-built man. He was dyspnœic and cyanosed at rest, but there was no clubbing of the fingers. The apex rate was 110 a minute and the rhythm was auricular fibrillation. The blood pressure was 110/75; the jugular veins were distended to a height of $4 \mathrm{~cm}$. above the sternal angle in the erect posture. There was no other clinical evidence of heart failure. The apex beat was in the sixth interspace outside the mid-clavicular line. There was no thrill. The first heart sound was split at the apex, and the second sound at the left border of the sternum was split but not exceptionally loud. A very soft early diastolic murmur was later heard to the left of the sternum. A blood count showed 7,410,000 red cells per c.mm. and hæmoglobin $17 \cdot 8 \mathrm{~g}$. per $100 \mathrm{ml}$.

Radioscopy on admission showed a very large heart with apparent marked enlargement of the right atrium and right ventricle and slight enlargement of the left atrium but no dilatation of the pulmonary artery; there was pulmonary congestion but no hilar dance. The heart rate slowed in response to digitalis. Next day the apex rate was 80 a minute and the lungs were free from radiological signs of congestion (Fig. 1).

The electrocardiogram showed auricular fibrillation and right bundle branch block. Regular rhythm returned two days after cardiac catheterization and has since been maintained; the bundle branch block persists (Fig. 3).

Atrial septal defect was first suspected but the absence of enlargement of the pulmonary artery and of a hilar dance with such a large heart were against this diagnosis (Bedford et al., 1941). 


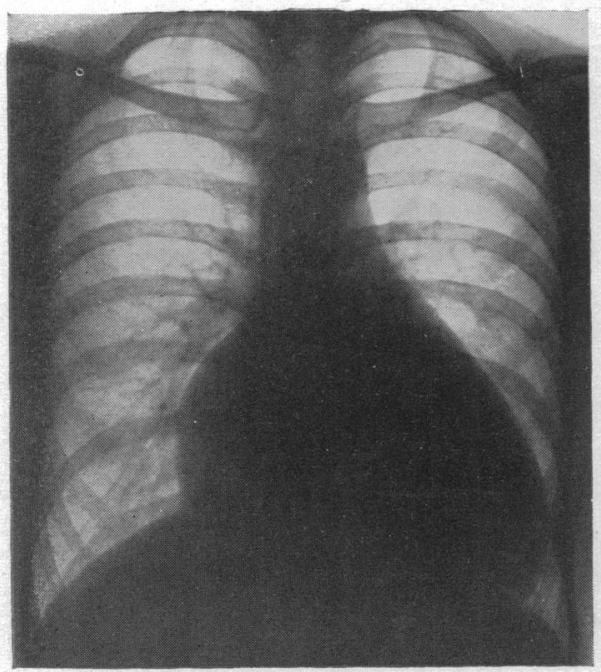

FIG. 1.-Teleradiogram, showing a large heart with prominent right atrium, but with no obvious enlargement of the pulmonary trunk and its branches.

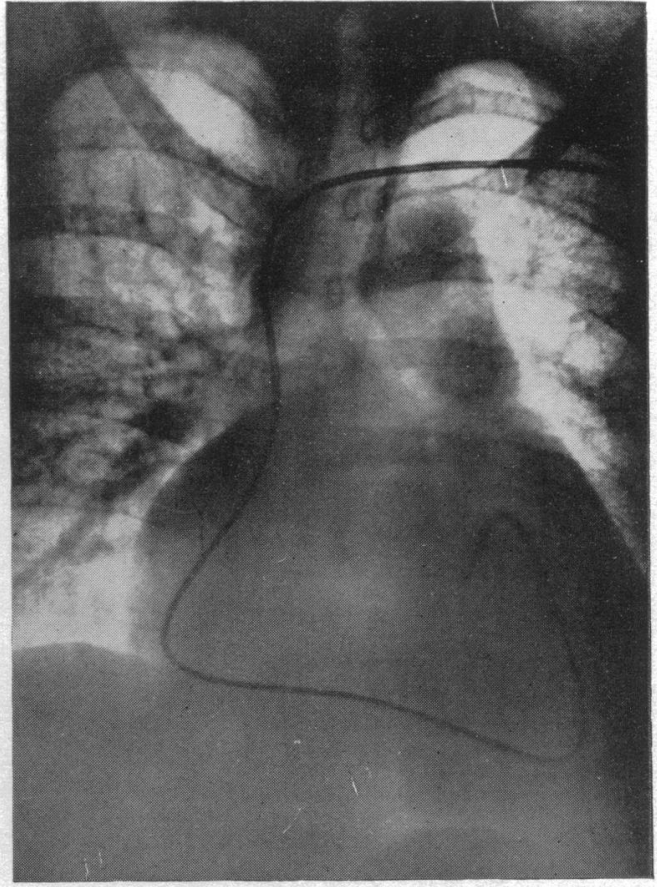

Fig. 2.-Film showing the catheter looped in the outflow portion of the right ventricle.

Cardiac catheterization was carried out. The catheter tip passed easily into the right ventricle and pulmonary artery describing a wide arc along the periphery of the cardiac shadow. The transition from atrial to ventricular pulsation occurred midway between the right and left borders of the heart, accompanied by only a slight rise in the mean pressure. The catheter could be made to loop in the upper part of the right ventricle in an unusual manner, and as the tip descended it met an obstruction at the same point each time (Fig. 2); pressure readings and blood samples confirmed that it was still in the ventricle. The impression gained was of an enormous right atrium and ventricle and of an outflow chamber in which the arrest of the catheter tip seemed compatible with a displaced tricuspid leaflet.

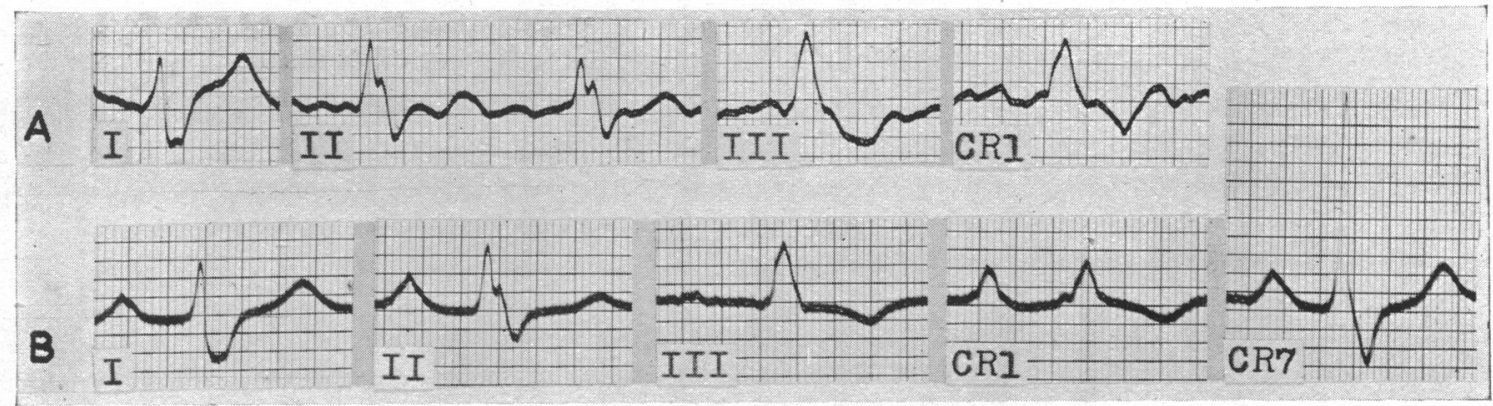
FIG. 3.-Electrocardiograms showing right bundle branch block. (A) Auricular fibrillation. (B) Normal rhythm
(see text). 


$\quad$ Site
Superior vena cava
Right atrium
Right ventricle
Main pulmonary artery
Femoral artery

Mean pressure in mm.Hg. Percentage oxygen relative to right atrium saturation

$\begin{array}{ll}7 \cdot 5 & 60 \\ 7 & 68 \\ 9-10 & 68 \\ 14 & 69 \\ - & 91\end{array}$

An angiocardiogram showed a very large right atrium two seconds after injection (Fig. 4A). One second later the whole heart shadow was opacified and the contrast medium was present in both pulmonary artery and aorta (Fig. 4B). There was poor filling of the pulmonary vessels and some opacification of the heart was still seen up to ten seconds.

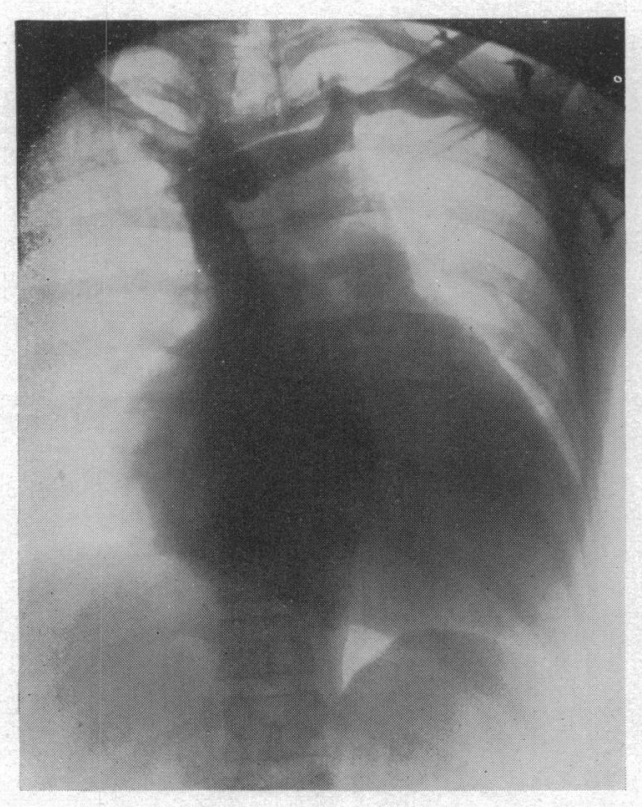

A

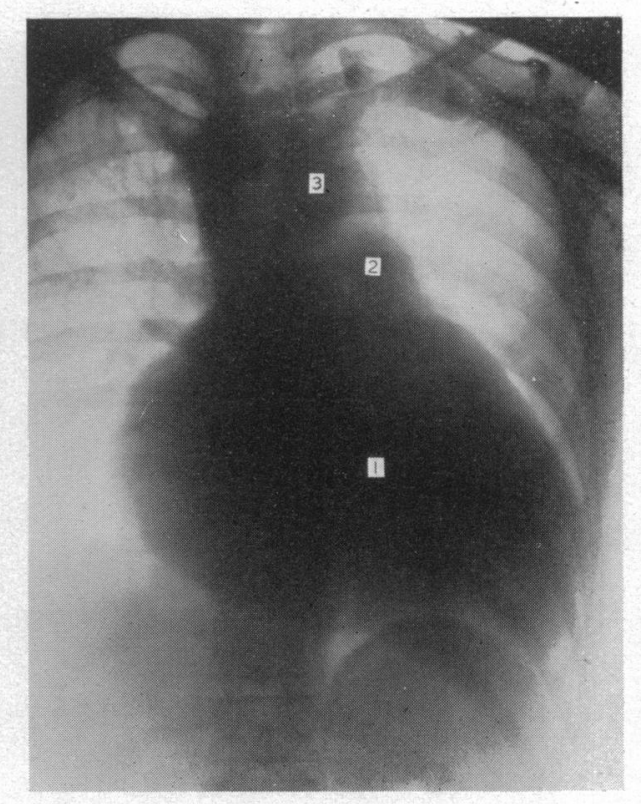

B

FIg. 4.-Angiocardiogram. (A) Two seconds after injection. Large right atrium outlined. (B) Three seconds after injection. Whole heart opacified (1), simultaneous filling of pulmonary artery (2) and of aorta (3).

\section{Summary}

The diagnosis of Ebstein's malformation with atrial septal defect seems probable in this case on the following grounds.

(1) A very large heart with particular enlargement of the right atrium and right ventricle without enlargement of the pulmonary artery and its branches in a patient with congenital heart disease who shows only slight cyanosis and early cardiac disability at 26 years.

(2) Cardiac arrhythmia and right bundle branch block.

(3) Low pressures on the right side of the heart with a very small pressure gradient between the atrium and the ventricle.

(4) Great enlargement of both right atrium and ventricle, including the outflow portion, shown by catheterization and the angiocardiogram.

(5) Suggestive evidence of displacement of the tricuspid valve.

(6) A large atrial septal defect with a shunt in both directions. 


\section{REFERENCES}

Baker, C., Brinton, W. D., and Channell, G. D. (1950). Guy's Hosp. Rep., 99, 247.

Bedford, D. E., Papp, C., and Parkinson, J. (1941). Brit. Heart J., 3, 37.

Brown, J. W. (1950). Congenital Heart Disease. London, Staples Press, p. 226.

Engle, M. A., Payne, T. P. B., Bruins, C., and Taussig, H. B. (1950). Circulation, 1, 1246.

van Lingen, B., McGregor, M., Kaye, J., Meyer, M. J., Jacobs, H. D., Braudo, J. L., Bothwell, T. H., and Elliott, G. A. (1952), Amer. Heart J., 43, 77.

Reynolds, G. (1950). Guy's Hosp. Rep., 99, 276.

Soloff, L. A., Stauffer, H. M., and Zatuchni, J. (1951). Amer. J. med. Sci., 222, 554.

Taussig, H. B. (1947). Congenital Malformations of the Heart. New York, Commonwealth Fund, p. 517.

\section{EDITORIAL Note}

Dr. Paul Wood informs me that among the patients he has diagnosed as Ebstein's disease, four or five have had catheterization and one died suddenly during this. At Guy's Hospital I have made the diagnosis in ten cases, two of whom were acyanotic and the others cyanotic. Six of these have had catheterization and one died, almost certainly as the result of intracardiac thrombosis.

We have heard of other deaths and complications arising after catheterization in cases of Ebstein's disease, and think that as the diagnosis can often be made on clinical grounds catheterization should not be carried out unless there are very special reasons for it. 